\title{
The Effect of Replacing Fine Silica with Fine Phosphate Waste (Russaifa mine) on the Compressive Strength of Mortar and Concrete: A Case Study in Jordan
}

\author{
Hesham Alsharie $^{1} \&$ Eng. Omar Alayed ${ }^{1}$ \\ ${ }^{1}$ Department of Civil Engineering, Jerash University, Jerash, Jordan \\ Correspondence: Hesham Alsharie, Department of Civil Engineering, Jerash University, Jerash, Jordan. E-mail: \\ h.alsharea@jpu.edu.jo
}

Received: April 2, 2019

Accepted: May 5, 2019

Online Published: May 30, 2019

doi:10.5539/mas.v13n6p89

URL: https://doi.org/10.5539/mas.v13n6p89

\begin{abstract}
It is known that the dumping of Phosphate wastes from Phosphate factories and mines has a negative effect on the environment. In an effort to reduce dumping, this study examines the possible reuse of this waste as a replacement for the fine sand of silica in mortar and concrete. Phosphate waste replaces silica with the following by-weight percentages: $0 \%, 10 \%, 25 \%, 50 \%$ and $100 \%$. To check the feasibility of such reuse, 30 mortar cubes, 30 concrete cubes, and 20 concrete cylinders were prepared for testing to achieve a compressive strength of $25 \mathrm{MPa}$ according to ASTM (211.1-81). The tests performed in this paper are conducted to the following samples: $(50 * 50 * 50 \mathrm{~mm})$ mortar samples, $(150 * 150 * 150 \mathrm{~mm})$ concrete cubes, and $(150 * 300 \mathrm{~mm})$ concrete cylinders. The samples were left in curing for a period of 7 days for some samples, and others for 28 days. The results show that the use of Phosphate wastes increased the compressive strength of mortar by $29 \%$. In concrete cubes, the use of Phosphate wastes increased compressive strength by $26 \%$. In concrete cylinders, the use of Phosphate wastes increased the compressive strength by $34 \%$. Subsequently, it is proposed that the stone squanders of Phosphate be utilized as an alternative to fine silica, and they demonstrated their quality through the basic tests of aggregate. The increase in stone strength is attributed to Phosphate waste as it has less absorption. The increase in the strength of Phosphate sand is due to the presence of chemical substances that increase the strength of its cohesion, such as TCP (Tricalcium Phosphate) (40.72\%), $\mathrm{P}_{2} \mathrm{O}_{5}$ (Phosphate pentoxide) (18.64\%), $\mathrm{CaO}$ (Calcium oxide) $(28.22 \%)$ and $\mathrm{SiO}_{2}$ (Silicon dioxide) (44.45\%). The percentage of CL (Chlorine) is minimal (0.01\%).
\end{abstract}

Keywords: compressive strength, environmental effect, cost, silica (pure), Phosphate wastes, mortar (M), and concrete $(\mathrm{C})$

\section{Introduction}

Phosphate was found in Jordan in 1908 in the two districts of Russaifa and Al-Hassa during construction of the Hejaz Railway. Interest was first shown in the commercial mining of Phosphates in 1935 in Russaifa in figure 2, where the Phosphate Company was established in 1942. However, the war of 1948 brought business to a halt. In 1949 , the organization was set up as a limited liability company in 1953, it was reopened as a public limited company. In 1962, Al-Hassa mine went into production with an upper annual limit of approximately one million tons, followed by Al-Abiad mine in 1979, and Eshidiya mine in (1988). The Hashemite Kingdom of Jordan has the fifth biggest reserve of Phosphate on the planet with an estimated 3.7 billion tons, 1.25 billion tons of which are owned by Jordan Phosphate Mines Company, making it the second biggest exporter and sixth biggest producer of Phosphate in the world. Production exceeds seven million tons of Phosphate every year, with an expected increase planned for 2017. Beyond the referenced reserves, the Natural Resources Authority made a gigantic discovery of Phosphate in Eshidiya in 1974 [1]. 


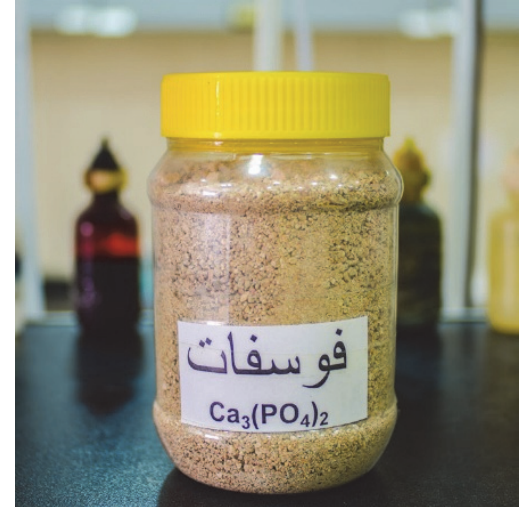

(a)

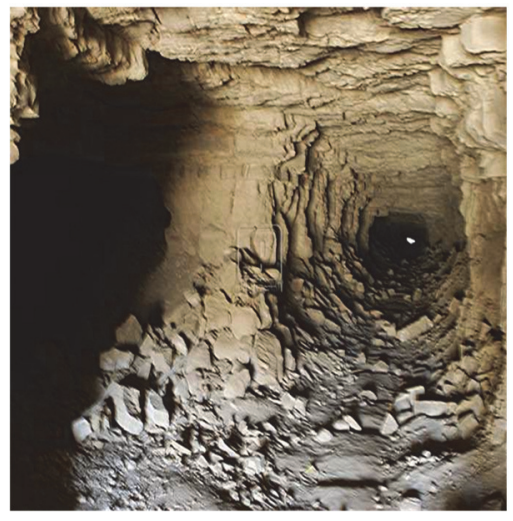

(b)

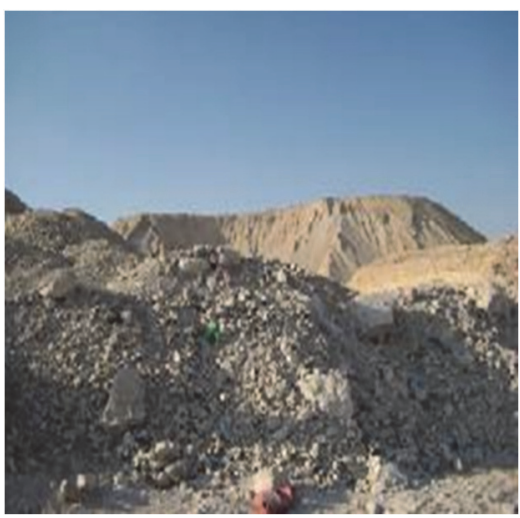

(c)

Figure 1. (a) Phosphate wastes (Ca3 (PO4)2); (b \& c) Phosphate mines in Russaifa

It is possible, by applying certain additives, to make Phosphate wastes resulting from Phosphate (Ca3 (PO4)2) sorting suitable for use in agriculture as fertilizer, thus decreasing economic losses. Moreover, these waste materials have significant effects on environmental pollution, so it is necessary to find a scientific and proper solution to reducing the amount of waste by finding other ways of utilizing it. The concern of this paper is the use of Phosphate wastes, without any additives, in concrete and mortar production to improve the compressive strength of concrete and to enhance the workability and durability of concrete. Thus testing this by replacing various proportions of silica with Phosphate waste material.

\section{Literature Review}

This literature review provides the fundamental background information on concrete technology in general, along with the materials used for mortar and concrete manufacturing with a strong focus on concrete aggregate. Both fine and coarse concrete aggregate are reviewed in terms of their properties, and the testing procedures utilized in the portrayal of concrete aggregate are additionally surveyed.

Mortar is a workable paste used to bind building blocks such as stones, bricks, and concrete masonry units together, fill and seal the irregular gaps between them, and sometimes add decorative colors or patterns in masonry walls. In its broadest sense, mortar includes pitch, asphalt, and soft mud or clay, such as is used between mud bricks. The term mortar comes from the Latin mortarium, meaning crushed [2].

Concrete is displayed incorporating its acoustic qualities with reference to coarse aggregate and customary solid, porosity has been recognized as a standout amongst the most unequivocal properties influencing the physical, mechanical, and acoustic attributes of cement, thusly, writing on porosity of coarse aggregate and cement is checked on [3].

Concrete is a blend of paste and aggregates (rocks). The paste is basically made out of portland bond and water, which coats the outside of the fine (little) and coarse (bigger) totals. Through a progression of substance responses 
called hydration, the glue solidifies and gains solidarity to frame the stone-like mass known as concrete [4].

Phosphorite, Phosphate rock or shake Phosphate is a non-detrital sedimentary rock which contains high measures of Phosphate-bearing minerals. The Phosphate substance of phosphorite is no less than 15 to $20 \%$. The Phosphate minerals predominantly found in phosphorite are hydroxyapatite and fluorapatite. Phosphate minerals contain approximately $18.5 \%$ phosphorus by weight and if phosphorite contains around $20 \%$ of these minerals, phosphorite is about $3.7 \%$ phosphorus by weight, hugely outweighing the normal sedimentary shake substance of under $0.2 \%$ [5].

Phosphate is a natural substance consisting mainly of calcium Phosphate (Ca3 (PO4)2), which is low in water so it is not used directly, until after undergoing treatment to improve its quality by drying and purifying it (removal of organic matter and carbon dioxide, and separation from clay). Phosphate fertilizers used in agriculture and phosphoric acid (H3PO4) represent the most important Phosphate derivatives. The quality of Phosphate is measured by the proportion of phosphorus pentoxide [6].

The area of Russaifa in central Jordan, and Al-Hassa and Eshidiya in the south of the Kingdom, are the sites of Phosphate extraction, although work has stopped in Russaifa due to the resulting dust and its impact on the population. Thus, extraction is now limited to the area of Al-Hassa. Jordan Phosphate Mines Company produces important industrial materials such as phosphoric acid, which is used in the manufacture of medicines and chemical fertilizers [7].

Phosphate mining produces sand tailings that are nearly sterile and almost void of plant nutrients (except for relatively insoluble P). Tailings are pumped onto sections of land to a depth of 5 to 7 meters after the Phosphate has been removed in the flotation process. The reclamation of sand tailings presents a unique challenge in that there is no organic matter present and fertility verges on zero. An investigation was initiated in May 1968 to study the effects of compost and fertilizer on sand tailings. Composted municipal refuse (compost) was incorporated into the top $15 \mathrm{~cm}$ of tailings at rates of 35 and 70 metric tons/ha with and without N-P-K fertilizer. Compost and fertilizer were reapplied in 1969 [8].

This paper presents the results of an experimental investigation into the effect of using Phosphate wastes as fine aggregate on mortar and concrete cube samples. Phosphate wastes were used as $10 \%, 25 \%, 50 \%$ and $100 \%$ replacement of fine aggregate in mortar and concrete mixtures. The tests performed in this paper were conducted on the following samples: $(50 * 50 * 50 \mathrm{~mm})$ mortar samples, $(150 * 150 * 150 \mathrm{~mm})$ concrete cubes, and $(150 *$ $300 \mathrm{~mm}$ ) concrete cylinders. For all tests, the cubes were left in curing for a period of 7 , and 28 days. The results show that the use of Phosphate wastes increased the compressive strength of mortar by $29 \%$. In concrete cubes, the use of Phosphate wastes increased compressive strength by $26 \%$. In concrete cylinders, the use of Phosphate wastes increased the compressive strength by 34 .

\section{Objectives of the Research}

The aim of this investigation is to study the possibility of using the Phosphate wastes in the production of mortar and concrete, to increase the compressive strength of mortar and concrete when adding specific proportions of Phosphate wastes within the standard specifications.

\section{Methodology}

To accomplish these objectives, experimental tests were conducted. A portion of these tests were obtained on fundamental materials. Some tests were conducted on the raw materials that were collected from Russaifa such as aggregate and Phosphate wastes. Hence, to get the design properties of these materials, the conducted tests were:

1. Sieve Analysis [9]

2. Atterberg limits (Liquid limit and Plastic limit, Plasticity index) [10]

3. Specific Gravity [11]

4. Absorption [11]

5. Moisture content [12].

In order to get the appropriate quantity of Phosphate wastes mixture that provides an improvement to mortar [13], and concrete properties, the samples were divided into five categories according to the ratio of Phosphate wastes to fine silica. In each category, six cube specimens and four cylinders were prepared and tested. The categories are:

1. Three cube and Two-cylinder specimens with null Phosphate wastes

2. Three cube and Two-cylinder specimens with $10 \%$ Phosphate wastes 
3. Three cube and Two-cylinder specimens with $25 \%$ Phosphate wastes

4. Three cube and Two-cylinder specimens with 50\% Phosphate wastes

5. Three cube and Two-cylinder specimens with $100 \%$ Phosphate wastes

Once the mortar and concrete samples were prepared, they were subjected to compressive tests [14], and slump tests [15].

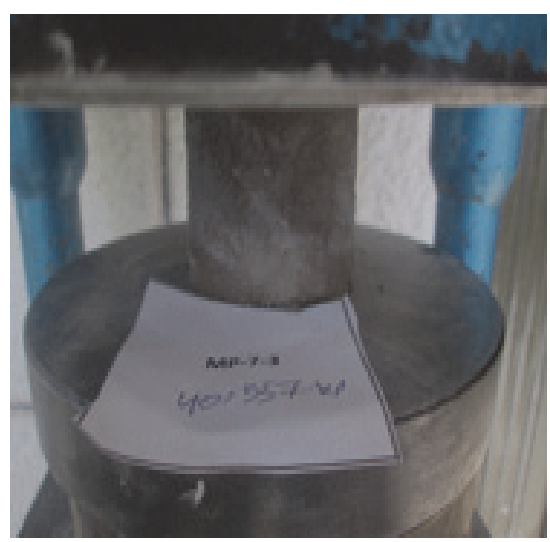

(a)

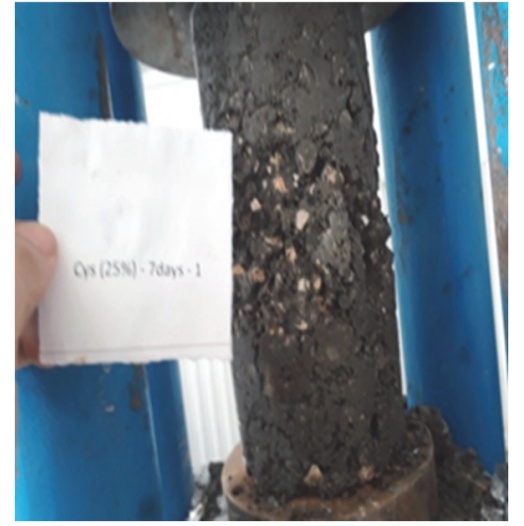

(b)

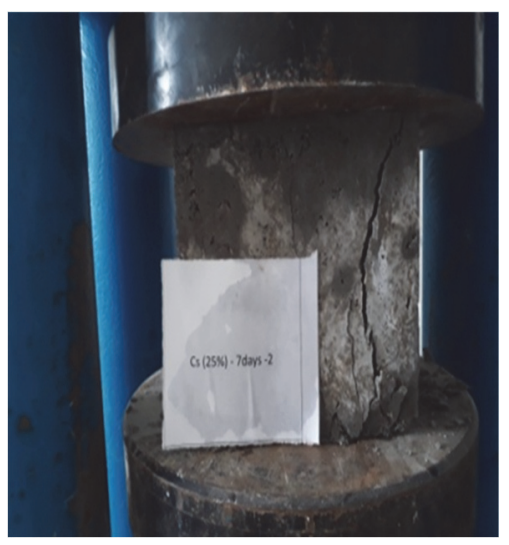

(c)

Figure 2. Compressive strength testing of (a) Pure mortar cubes, (b) Phosphate wastes fine concrete cubes, (c) Phosphate wastes fine concrete cylinders

The figure 2, 3 mortar and concrete samples were prepared. The samples included a total of 30 mortar, 30 cubes, and 20 cylinders.

First, all mortar samples were classified to five main categories, depending on the ratio to silica aggregate (P, S): Three cube specimens with null Phosphate wastes (MP), three cube specimens with $10 \%$ Phosphate wastes (MS10\%), three cube specimens with 25\% Phosphate wastes (MS25\%), three cube specimens with 50\% Phosphate wastes (MS50\%), and three cube specimens with 100\% Phosphate wastes (MS100\%).

The following Table (1) shows the detailed percentages of cement and fine aggregate ratio, water and Phosphate wastes that were used to prepare the cube mortar specimens:

Table 1. The mix design ratio details of cube mortar specimens

\begin{tabular}{lllll}
\hline Sample (\%) & Cement $(\mathrm{kg})$ & Water $(\mathrm{ml})$ & Sand $(\mathrm{kg})$ & Phosphate waste $(\mathrm{kg})$ \\
\hline MP & 0.500 & 0.243 & 1.375 & 0 \\
MS (10\%) & 0.500 & 0.243 & 1.24 & 0.1375 \\
\hline
\end{tabular}




\begin{tabular}{lllll}
\hline MS (25\%) & 0.500 & 0.243 & 1.031 & 0.344 \\
MS (50\%) & 0.500 & 0.243 & 0.675 & 0.7 \\
& & & & $1.375 \mathrm{~kg}$ \\
MS (100\%) & $0.500 \mathrm{~kg}$ & $0.243 \mathrm{ml}$ & 0 & .
\end{tabular}

Note: MP7.1: Mortar pure age seven days cube number one; MS10\% 28.2: Mortar 10\% Phosphate wastes ratio of silica age twenty-eight cube number two; and MS100\% 7.3: Mortar 100\% Phosphate wastes ratio of silica seven days cube number three.

Second, all concrete samples were, in addition to being in the five main categories of cube and five cylindrical, dependent on the ratio of silica (P,S), three cube specimens with null Phosphate wastes (CP) and three cube specimens with $10 \%$ Phosphate wastes (CS10\%), three cube specimens with 25\% Phosphate wastes (CS25\%), three cube specimens with 50\% Phosphate wastes (CS50\%) and three cube specimens with $100 \%$ Phosphate wastes $(\mathrm{CS} 100 \%)$. While two cylindrical specimens with null Phosphate wastes (CyP) and two cylindrical specimens with $10 \%$ Phosphate wastes (CyS10\%), two cylindrical specimens with $25 \%$ Phosphate wastes (CyS25\%), two cylindrical specimens with 50\% Phosphate wastes (CyS50\%) and two cylindrical specimens with $100 \%$ Phosphate wastes (CyS100\%).

Following determination of engineering properties (grain span distribution, specific gravity) of crude materials (for example, coarse/fine aggregate, also sand), a mix design may be conducted with the example as stated by those classifications specified previously. The values of moisture content and absorption in the mix were taken into consideration.

The following Table (2) shows the detailed percentages of cement and fine aggregate ratio, water and Phosphate wastes that were used to prepare the cube and cylindrical specimens:

Table 2. The mix design ratio details of cube and cylindrical specimens

\begin{tabular}{llllll}
\hline Sample (\%) & $\begin{array}{l}\text { Water } \\
(\mathrm{kg})\end{array}$ & $\begin{array}{l}\text { Cement } \\
(\mathrm{kg})\end{array}$ & $\begin{array}{l}\text { Coarse } \\
\text { Aggregate } \\
(\mathrm{kg})\end{array}$ & $\begin{array}{l}\text { Fine } \\
\text { Aggregate } \\
(\mathrm{kg})\end{array}$ & $\begin{array}{l}\text { Phosphate } \\
\text { Waste } \\
(\mathrm{kg})\end{array}$ \\
\hline CP and CyP & 7.3 & 14.68 & 41.8 & 32.256 & 0 \\
CS $(10 \%)$ and CyS (10\%) & 7.1 & 14.68 & 41.8 & 29.026 & 3.43 \\
CS $(25 \%)$ and CyS (25\%) & 6.79 & 14.68 & 41.8 & 24.192 & 8.57 \\
CS (50\%) and CyS (50\%) & 6.29 & 14.68 & 41.8 & 16.128 & 17.143 \\
CS (100\%) and CyS (100\%) & 5.271 & 14.68 & 41.8 & 0 & 34.29 \\
\hline
\end{tabular}

Note: CP7.1: Cube concrete pure age seven days cube number one, CS10\%28.2: Cube concrete 10\% Phosphate wastes ratio of silica age twenty-eight cube number two, and CyS25\%7.3: Cylindrical concrete 25\% Phosphate wastes ratio of silica seven days cube number three and CyS50\%28.1: Cylindrical concrete 50\% Phosphate wastes ratio of silica age twenty-eight cube number one.

\section{Results and Discussion}

\subsection{Sieve Analysis of Phosphate Wastes}

Table 3. Illustrating the sieve analysis of Phosphate wastes

\begin{tabular}{lllllll}
\hline No. of Sieve & $\begin{array}{l}\text { Mass of passing } \\
(\mathrm{g})\end{array}$ & $\begin{array}{l}\text { Mass } \\
\text { retained } \\
(\mathrm{g})\end{array}$ & of & $\begin{array}{l}\text { Cumulative } \\
\text { Percentage } \\
\text { passing } \%\end{array}$ & $\begin{array}{l}\text { Cumulative } \\
\text { Percentage } \\
\text { retained \% }\end{array}$ & $\begin{array}{l}\text { ASTM fine } \\
\text { aggregate }\end{array}$ \\
\hline 8 & 145 & 145 & 85.4 & 14.6 & 100 \\
16 & 150 & 70.3 & 29.7 & $90-100$ \\
\hline
\end{tabular}




\begin{tabular}{llllll}
\hline 30 & 415 & 120 & 58.3 & 41.7 & $60-90$ \\
50 & 720 & 305 & 27.6 & 72.4 & $20-60$ \\
100 & 945 & 225 & 5.0 & 95 & $0-30$ \\
200 & 975 & 30 & 2.0 & 98 & $0-10$ \\
\hline
\end{tabular}

Table 3 shows the readings of the sieve analysis of Phosphate wastes. It was noted that the value of fineness modulus was 2.534 and this indicates their conformity with Jordanian and American specifications. The fineness modulus has a significant impact on concrete. The smaller the modulus value, the greater the amount of soft material in the mixture (smooth gradient), and if its value is large, this indicates a rough gradient of the mark in the value ranges (2.3-3.1) [16].

\subsection{Atterberg Limits (Liquid Limit and Plastic Limit, Plasticity Index) of Phosphate Wastes}

Table 4. The liquid limit, plastic limit, and plasticity index of Phosphate wastes

\begin{tabular}{lll}
\hline Liquid limit (LL) & Plastic limit (PL) & Plasticity index (PI) \\
\hline 15.47 & 13.92 & 1.55 \\
\hline
\end{tabular}

Table 4 shows that the readings of the liquid limit, plastic limit, and plasticity index of Phosphate wastes. The Atterberg limits are a basic measure of the critical water contents of a fine-grained it was noted that the value of plasticity index (PI) $1.5<7$ fine-grained descriptions the slightly plastic [17].

\subsection{Specific Gravity and Absorption of Phosphate Wastes}

Table 5. The specific gravity and absorption of Phosphate wastes

\begin{tabular}{ll}
\hline Weight of dry sample (A) (g) & 489 \\
\hline Weight of SSD (B) (g) & 500 \\
Weight of (flask + water + sample) (C) (g) & 1622 \\
Weight of (flask + water) (D) (g) & 1320 \\
Specific gravity (dry sample) a/(b+c-d) & 2.47 \\
Specific gravity SSD b/(b+d-c) & 2.525 \\
Specific gravity Apparent a/(a+d-c) & 2.615 \\
Absorption ratio (b-a/a)*100 (\%) & 2.249 \\
\hline
\end{tabular}

Table 5 shows the readings of the specific gravity and absorption of Phosphate wastes. It was found that the value of the specific gravity is greater than 2.4, which indicates the quality of the waste. Also, the absorption [18] ratio is less than $6 \%$, which is in accordance with Jordanian and American specifications.

\subsection{Moisture Content}

Table 6. The moisture content of Phosphate wastes

\begin{tabular}{lll}
\hline Wet weight $(\mathrm{g})$ & Dry weight $(\mathrm{g})$ & Weight percentage (\%) \\
\hline 1080 & 995 & 8.54 \\
\hline
\end{tabular}

Table 6 shows that the readings of the moisture content of Phosphate wastes and attributed was $8.54 \%$. The 
moisture condition of aggregates in concrete is very important. We are all familiar with Abrams Law [19] which states that, all other things being equal, compressive strength of concrete is dependent on the ratio of mass of water to cementitious material. However, what is less understood is that the water-cement ratio controls the pore volume and pore sizes in the concrete, thereby determining not only the strength but also durability. This ratio was taken into account in mix design.

\subsection{The Compressive Strength Test Result}

Table 7. The average compressive strength of cement mortar of Phosphate waste and pure

\begin{tabular}{lll}
\hline Samples & $\begin{array}{l}\text { Average (MPA) } \\
7 \text { day }\end{array}$ & $\begin{array}{l}\text { Average (MPA) } \\
28 \text { day }\end{array}$ \\
\hline MP & 16.34 & 20.61 \\
MS (10\%) & 21.7 & 24.45 \\
MS (25\%) & 26.31 & 27.64 \\
MS (50\%) & 26.98 & 28.76 \\
MS (100\%) & 27.76 & 29.02 \\
\hline
\end{tabular}

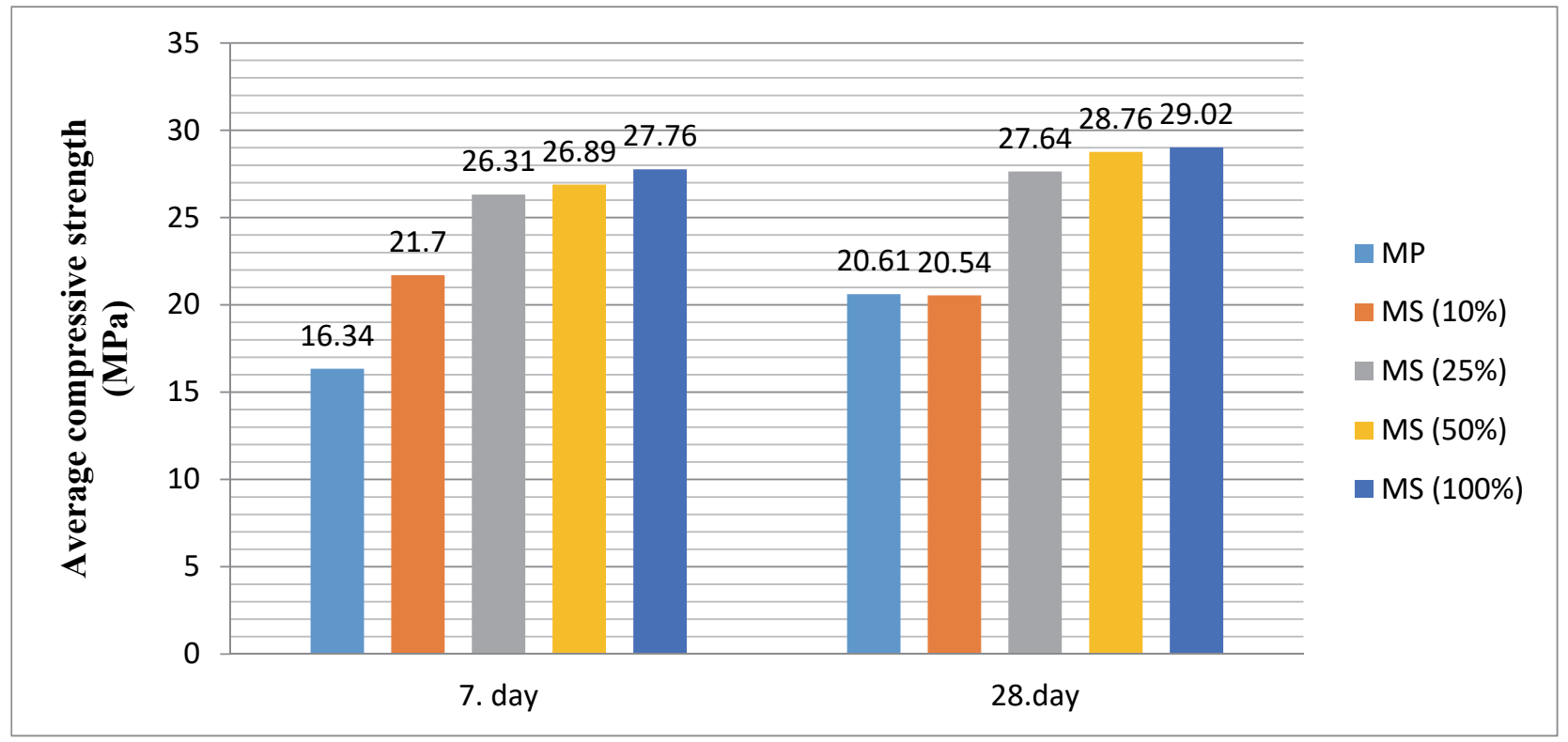

Figure 3. Average compressive strength test conducted on the mortar for MS: Mortar Phosphate wastes ratio of silica, MP: Mortar pure

Table 7 and Figure 3 show the results of compressive strength of cement mortar specimens at an age of 7 and 28 days. Results showed that the mortar $10 \%$ Phosphate wastes ratio of silica increased the compressive strength of cement mortar by a ratio of $24 \%$ and $15 \%$ an age of 7 and 28 days, respectively. The compressive strength of cement mortar with mortar 25\% Phosphate wastes ratio of silica at an age of 7 and 28 days increased by a ratio of $37 \%$ and $25 \%$ respectively and mortar $50 \%$ Phosphate wastes ratio of silica increased the compressive strength of cement mortar by a ratio of $39 \%$ and $28 \%$ an age of 7 and 28 days, respectively. Finally, the compressive strength of cement mortar with mortar 100\% Phosphate wastes ratio of silica at an age of 7 and 28 days increased by a ratio of $41 \%$ and $29 \%$ respectively, as compared with mortar pure. 
Table 8. The average compressive strength of concrete cubes of Phosphate waste and pure

\begin{tabular}{lll}
\hline Samples & $\begin{array}{l}\text { Average (MPA) } \\
7 \text { day }\end{array}$ & $\begin{array}{l}\text { Average (MPA) } \\
28 \text { day }\end{array}$ \\
\hline CP & 20.966 & 27.4 \\
CS (10\%) & 23.70 & 34.83 \\
CS (25\%) & 24.81 & 36.12 \\
CS (50\%) & 27.07 & 38.91 \\
CS (100\%) & 31.48 & 42.38 \\
\hline
\end{tabular}

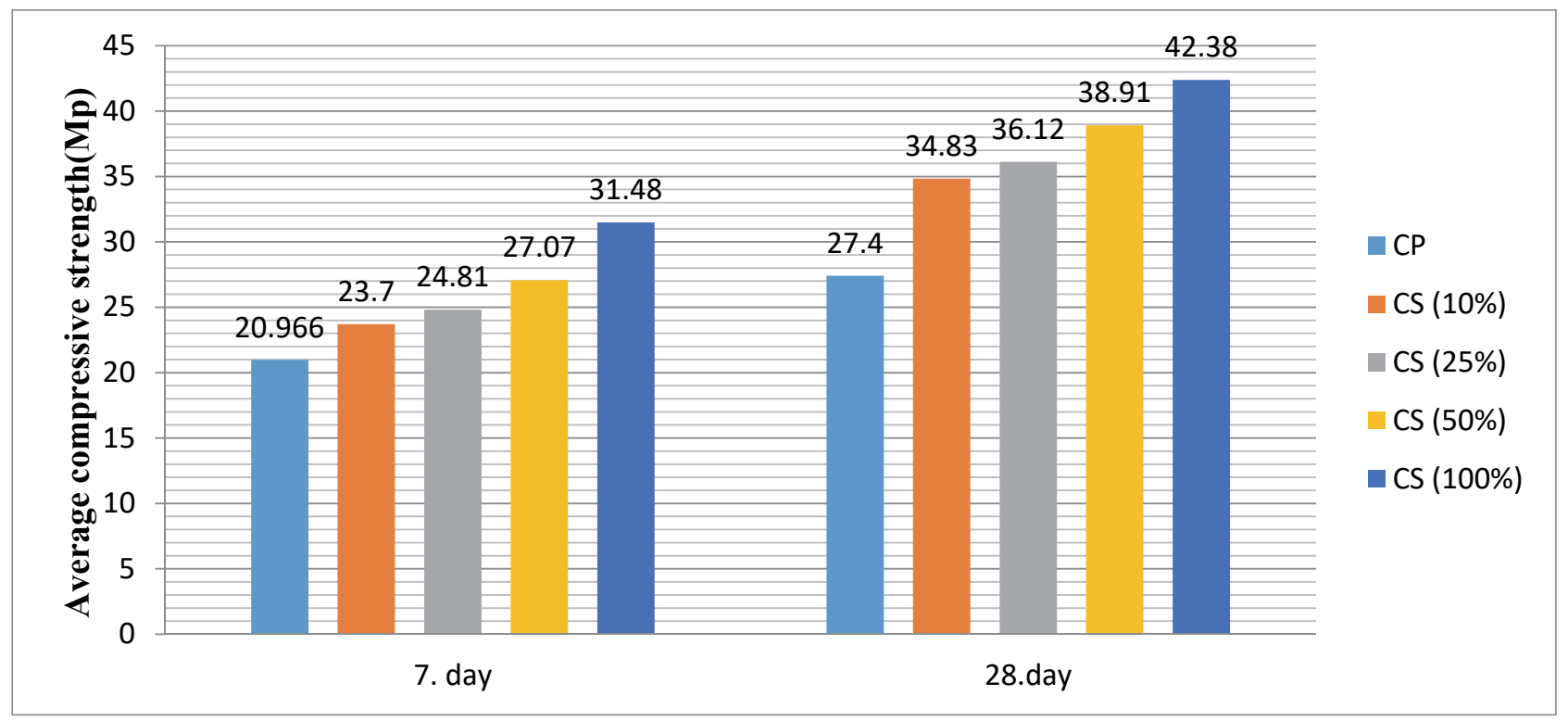

Figure 4. Average compressive strength test conducted on the concrete cubes for CS: Concrete Phosphate wastes ratio of silica; $\mathrm{CP}$ : Concrete pure

Table 8 and Figure 4 show the results of compressive strength of concrete cubes at an age of 7 and 28 days. Results showed that the concrete cubes $10 \%$ Phosphate wastes ratio of silica increased the compressive strength of concrete cubes by a ratio of $11.5 \%$ and $21.33 \%$ at an age of 7 and 28 days, respectively. The compressive strength of concrete cubes with $25 \%$ Phosphate wastes ratio of silica at an age of 7 and 28 days increased by a ratio of $15.5 \%$ and $24.1 \%$ respectively, and concrete cubes $50 \%$ Phosphate wastes ratio of silica increased the compressive strength of concrete cubes by a ratio of $22.5 \%$ and $29.5 \%$ at age of 7 and 28 days, respectively. Finally, the compressive strength of concrete cubes with $100 \%$ Phosphate wastes ratio of silica at an age of 7 and 28 days increased by a ratio of $33.4 \%$ and $35.3 \%$ respectively, as compared with concrete cubes pure.

Table 9. The average compressive strength of concrete cylinders of Phosphate waste and pure

\begin{tabular}{lll}
\hline Samples & $\begin{array}{l}\text { Average (MPA) } \\
7 \text { day }\end{array}$ & $\begin{array}{l}\text { Average (MPA) } \\
28 \text { day }\end{array}$ \\
\hline CyP & 17.535 & 18.2 \\
CyS (10\%) & 19.095 & 21.85 \\
CyS (25\%) & 20.85 & 24.34 \\
CyS (50\%) & 25.87 & 27.585 \\
CyS (100\%) & 28.305 & 31.3 \\
\hline
\end{tabular}




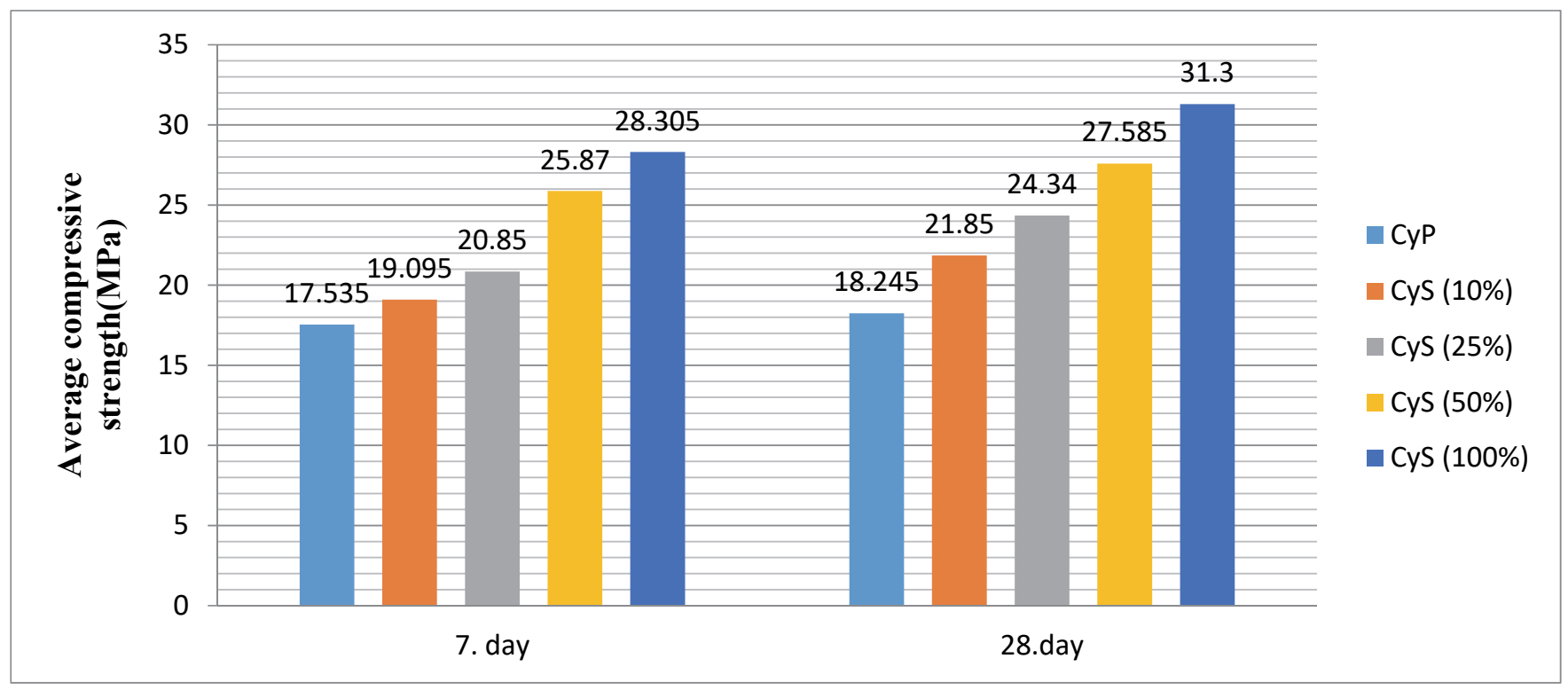

Figure 5. Average compressive strength that was conducted on the concrete cylinders for CyS: Concrete cylinders Phosphate wastes ratio of silica, CyP: Concrete cylinders pure

Table 9 and Figure 5 show the results of compressive strength tests on concrete cylinders at an age of 7 and 28 days. Results showed that the concrete cylinders 10\% Phosphate wastes ratio of silica increased the compressive strength of concrete cylinders by a ratio of $8.17 \%$ and $16.7 \%$ at an age of 7 and 28 days, respectively. The compressive strength of concrete cylinders with 25\% Phosphate wastes ratio of silica at an age of 7 and 28 days increased by a ratio of $15.9 \%$ and $25.2 \%$ respectively and concrete cylinders $50 \%$ Phosphate wastes ratio of silica increased the compressive strength of concrete cylinders by a ratio of $32.2 \%$ and $34 \%$ at an age of 7 and 28 days, respectively. Finally, the compressive strength of concrete cylinders with $100 \%$ Phosphate wastes ratio of silica at an age of 7 and 28 days increased by a ratio of $38 \%$ and $41.8 \%$ respectively, as compared with concrete cylinders pure.

\subsection{The Slump Test}

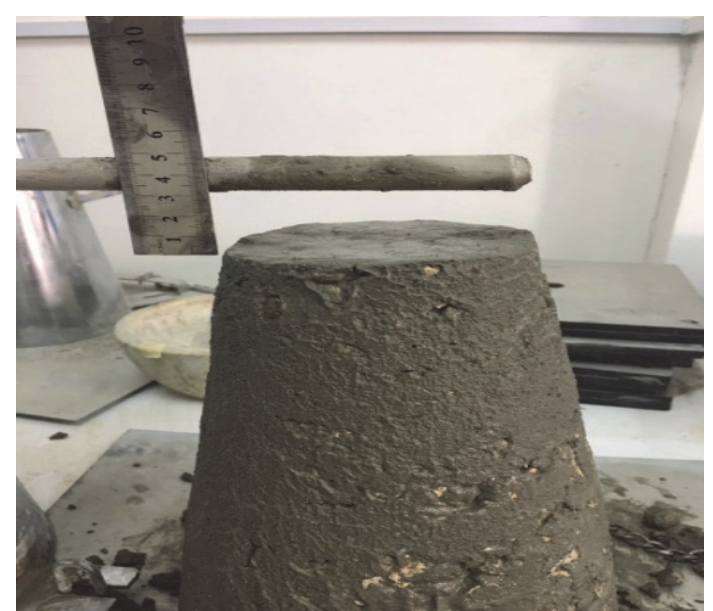

Figure 6. The slump test of Phosphate waste

Figure 6 shows the results of the slump test. The value was $50 \mathrm{~mm}$, which means medium slump (50-100mm) and value is equal to that in mix design. 


\section{Conclusion}

The following conclusions are drawn based on the laboratory test results used in this study. It showed that the Phosphate waste increased specific gravity by about 2.525 . With that said, Phosphate waste favorably affects absorption ratio by less than $6 \%$ and increases Phosphate waste compressive strength of cement mortar by $41 \%$. This is in compliance with Jordanian and American specifications. And compressive strength of concrete cube by applying 35\%, compressive strength of concrete cylindrical by apply $41.8 \%$. Using Phosphate waste increases mortar and concrete compressive strength more than two times compared to its pure strength. Finally, using Phosphate waste was recommended to produce mortar and concrete with high strength. Using Phosphate waste to produce mortar and concrete will reduce the negative effect on the environment and economy.

\section{Acknowledgement}

Special thanks to Engineer Ahmed Ibrahim Abuaita and Ahmed Mohammed Hamaideh for their help in the laboratory.

\section{References}

AASHTO T 85 and ASTM C 127: Specific Gravity and Absorption of Coarse Aggregate.

Alahram Group - is a global trading company. Our company was founded in 2011 in Egypt, in the name of Eng. Ahmed Hussien, Chairman.

American Society for Testing Materials ASTM C39/C39M, ASTM C39 / C39M - 17b Standard Test Method for Compressive Strength of Cylindrical Concrete Specimens.

ASTM C109 / C109M - 16a Standard Test Method for Compressive Strength of Hydraulic Cement Mortars (Using 2-in. or [50-mm] Cube Specimens).

ASTM C128 - 15 (Standard Test Method for Relative Density (Specific Gravity) and Absorption of Fine Aggregate).

ASTM C136 / C136M - 14 (Standard Test Method for Sieve Analysis of Fine and Coarse Aggregates).

ASTM C143 in the United States, IS: 1199 - 1959 in India and EN 12350-2 in Europe.

C. C. Hortenstine and D. F. Rothwell.

Determining total moisture and free moisture in aggregate (coarse and fine) dotd designation: TR-106-11.

George F. Sowers, George B. Sowers.

Jordan Phosphate Mines Company Limited (JPMC).

Mehta and Monteiro. (1993). Concrete Structure, Properties, and Materials, Prentice-Hall, Inc., Englewood Cliffs, NJ.

Mortar holding weathered bricks.

Office of Engineering Construction and Maintenance Division (Materials Branch).

Phosphates - PubChem Public Chemical Database". The PubChem Project. USA: National Center of Biotechnology Information.

Punmia, Dr B. C., Jain, A. K., \& Jain, A. Kr. (2003-05-01). Basic Civil Engineering. Firewall Media. ISBN 9788170084037.

Seed, H. B. (1967). "Fundamental Aspects of the Atterberg Limits". Journal of Soil Mechanics and Foundations Div., 92(SM4), Retrieved from http://trid.trb.org/view.aspx?id=38900

USGS Minerals Year Book - Phosphate Rock A copy reserved March 22, 2018 on the Wi-Pak Mashin website.

WSDOT FOP for WAQTC T 27/T 11 Sieve Analysis of Fine and Coarse Aggregates.

\section{Copyrights}

Copyright for this article is retained by the author(s), with first publication rights granted to the journal.

This is an open-access article distributed under the terms and conditions of the Creative Commons Attribution license (http://creativecommons.org/licenses/by/4.0/). 